\title{
Wide dissemination of extended-spectrum $\beta$-lactamase-producing Escherichia coli in community residents in the Indochinese peninsula
}

This article was published in the following Dove Press journal:

Infection and Drug Resistance

23 January 2015

Number of times this article has been viewed

\author{
Tatsuya Nakayama' \\ Shuhei Ueda ${ }^{2}$ \\ Bui Thi Mai Huong ${ }^{3}$ \\ Le Danh Tuyen ${ }^{3}$ \\ Chalit Komalamisra ${ }^{4}$ \\ Teera Kusolsuk ${ }^{4}$ \\ Itaru Hirai ${ }^{2}$ \\ Yoshimasa Yamamoto ${ }^{1,5}$ \\ 'Global Collaboration Center, Osaka \\ University, Osaka, Japan; ${ }^{2}$ Faculty of \\ Medicine, University of The Ryukyus, \\ Okinawa, Japan; ${ }^{3}$ National Institute for \\ Nutrition, Hanoi, Vietnam; ${ }^{4}$ Faculty of \\ Tropical Medicine, Mahidol University, \\ Bangkok, Thailand; ${ }^{5}$ Osaka Prefectural \\ Institute of Public Health, Osaka, Japan
}

Correspondence: Yoshimasa Yamamoto Global Collaboration Center, Osaka University, 2-7 Yamadaoka, Suita,

Osaka 565-087I, Japan

Tel +8 I 668794442

Fax +8I 668794444

Email yyamamot@iph.pref.osaka.jp
Abstract: Recent studies have reported a widespread distribution of extended-spectrum $\beta$-lactamase (ESBL)-producing bacteria, not only in the nosocomial setting, but also in the community; some local communities in Southeast Asia have been reported to show a high prevalence of ESBL-producing bacteria. However, the details regarding the quantitative/qualitative state of ESBL-producing bacterial spread in Southeast Asia are currently unclear. Thus, the aim of this study was to assess the state of ESBL-producing bacterial spread in community residents from the Indochinese peninsula, as a representative region of Southeast Asia. In order to achieve this aim, local community residents in Laos and Vietnam were examined for fecal carriage of ESBLproducing Enterobacteriaceae, and the findings were compared with data from a previous study in Thailand which was conducted in the same manner as this study. Between $47.0 \%-70.2 \%$ of the Laotian and Vietnamese residents carried ESBL-producing CTX-M genotype Enterobacteriaceae. The most common sub-genotypes of CTX-M were CTX-M-1 (33.0\%-47.5\%) and CTX-M-9 (47.5\%-64.1\%), and these rates were similar among all three countries. Taken together, these results confirmed that ESBL-producing Enterobacteriaceae are widely disseminated in Indochinese countries, such as Thailand, Laos, and Vietnam.

Keywords: extended-spectrum $\beta$-lactamase (ESBL), rural residents, Indochinese peninsula, fecal carriage

\section{Introduction}

Multi-drug resistant bacteria are associated with persistent disease and are continuously expanding around the world, warranting increased attention. ${ }^{1}$ Extended-spectrum $\beta$-lactamases (ESBLs) are enzymes produced by Enterobacteriaceae, including Escherichia coli and Klebsiella pneumoniae, which invalidate $\beta$-lactam antibiotics, such as penicillin and cephalosporin. ${ }^{2}$ Recent studies have indicated a high prevalence of these ESBL-producing bacteria in communities in various Asian countries, ${ }^{3-6}$ and our previous studies revealed a relatively high prevalence of ESBL-producing Enterobacteriaceae in residents of local communities in Thailand. ${ }^{3,4}$ However, whether this high prevalence of ESBL-producing bacteria in the community is similar in other communities of the Indochinese peninsula remains to be elucidated. Therefore, in this study, two other communities from Laos and Vietnam were studied to determine the quantitative and qualitative states of ESBL-producing bacterial spread in this part of the world.

\section{Materials and methods}

\section{Specimen collection}

The study was conducted at a village in the Sawanaket province, Laos, in November 2012 and a community in Bavi, Hanoi, Vietnam, in June 2013. The two communities were 
selected to represent geographically different countries of the peninsula (Figure 1). A total of 57 and 198 asymptomatic resident volunteer participants were enrolled in Laos and Vietnam, respectively. One stool specimen was obtained from each participant using a transport swab with Cary-Blair transport media (Eiken Chemical, Tokyo, Japan). Written informed consent was obtained from each individual participating in the study. The study was approved by the ethics committee of Osaka University.

\section{Detection of ESBL-producing bacteria}

Stool specimens were plated on MacConkey agar (Nissui, Tokyo, Japan) supplemented with 1 and $2 \mathrm{mg} / \mathrm{L}$ cefotaxime (Tokyo Chemical Industry, Tokyo, Japan), in the case of Vietnam and Laos, respectively, (CTX-MacConkey) and incubated at $37^{\circ} \mathrm{C}$ for 24 hours. ESBL expression was confirmed by the disc diffusion method using cefotaxime and ceftazidime with and without clavulanic acid, as recommended by the Clinical and Laboratory Standards Institute (CLSI, Wayne, PA, USA); each set of samples was tested along with the CLSI quality control strains E. coli Americal Type Culture Collection (ATCC) (Manossos, VA, USA) 25922 and K. pneumoniae ATCC 700603. ${ }^{7}$ Positive isolates were identified using conventional biochemical tests with the API 20E (Sysmex-bioMerieux, Tokyo, Japan) and VITEK 2 (Sysmex-bioMerieux) system. ${ }^{8}$

\section{Detection of ESBL genes and genotyping}

Bacterial DNA was extracted by boiling suspensions of ESBL-producing isolates. DNA samples at a concentration of $1.0 \mathrm{ng} / \mu \mathrm{L}$ were used as polymerase chain reaction (PCR)

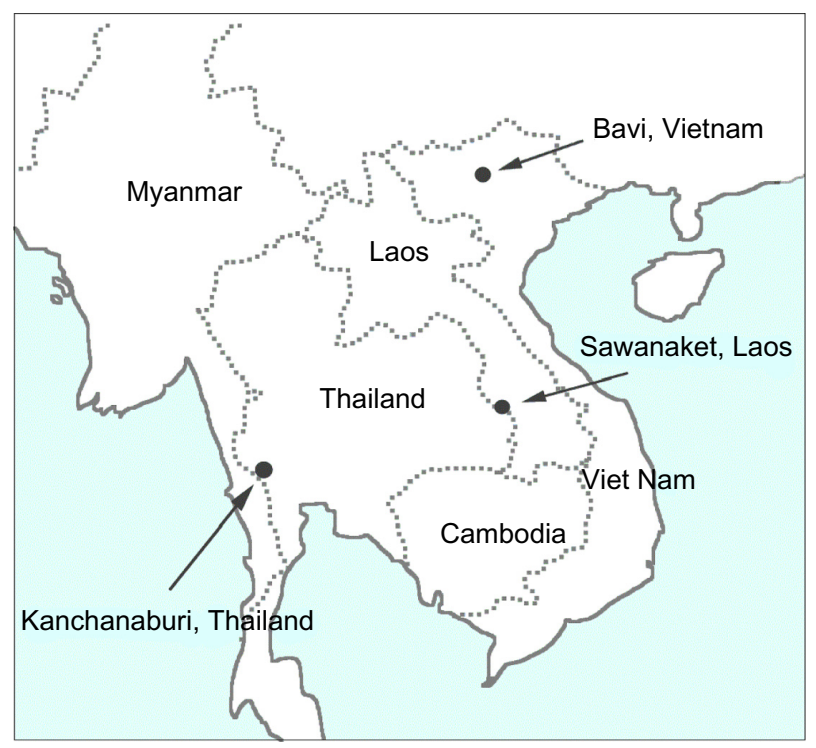

Figure I Research sites. templates, and the $b l a_{\mathrm{CTX}-\mathrm{M}}$, bla $a_{\mathrm{SHY}}$ and $b l a_{\mathrm{TEM}}$ genes were amplified using universal primers, as described previously. ${ }^{9}$ For genotyping of the $b l a_{\text {СТХ-м }}$ genes, four primer sets were used to amplify group-specific bla ${ }_{\text {СТХ-М }}$ genes, as described elsewhere, ${ }^{10}$ including the CTX-M-1, CTX-M-2, CTX-M-8, CTX-M-9, and CTX-M-25 groups. Phylogenetic grouping of identified $E$. coli was determined by triplex PCR using a combination of two genes (chuA and yjaA) and the DNA fragment TSPE4.C2, as described elsewhere. ${ }^{11}$ The PCR products were visualized by $2 \%$ agarose gel electrophoresis and staining with GelRed nucleic acid stain (Biotium, Hayward, CA, USA).

\section{Statistical analysis}

Statistical analysis was performed using the chi-squared test.

\section{Results}

A total of 57 Laotian and 198 Vietnamese local residents were investigated for the prevalence of ESBL-producing Enterobacteriaceae. The results showed that $71.9 \%$ of the Laotian residents and $51 \%$ of the Vietnamese residents had ESBL-producing Enterobacteriaceae in their stool specimens. All of the isolated ESBL-producing Enterobacteriaceae were identified as E. coli. The multiplex PCR detected that $70.2 \%$ of Laotian and $47 \%$ of Vietnamese residents possessed ESBL-producing bacteria with the CTX-M gene. The prevalence of ESBL-producing Enterobacteriaceae in the community assessed in Vietnam was significantly lower than that in Laos and Thailand (Table 1). However, the

Table I Prevalence of extended-spectrum $\beta$-lactamase-producing Enterobacteriaceae in residents of Indochinese countries

\begin{tabular}{llll}
\hline & Thailand $^{\text {a }}$ & Laos & Vietnam \\
\hline Sampling period & November 20I0 & November 20I2 & June 20I3 \\
No of participants & 417 & 57 & 198 \\
Age, mean & 47 & 47 & 31 \\
Age, range & $20-85$ & $17-75$ & $1-90$ \\
Sex, male (\%) & 38 & 18 & 52 \\
Phenotype & $69.3 \%(289)^{*}$ & $71.9 \%(4 I)^{* *}$ & $51.0 \%(101)$ \\
CTX-M gene & $65.7 \%(274)^{*}$ & $70.2 \%(40)^{* *}$ & $47.0 \%(93)^{\mathrm{b}}$ \\
CTX-M genotype groups & & \\
M-I group & $38.7 \%(106)$ & $47.5 \%(19)$ & $33.0 \%(34)$ \\
M-2 group & $0 \%(0)$ & $0 \%(0)$ & $1.0 \%(1)$ \\
M-8 group & $0.7 \%(2)$ & $5.0 \%(2)$ & $1.9 \%(2)$ \\
M-9 group & $60.6 \%(166)$ & $47.5 \%(19)$ & $64.1 \%(66)$ \\
\hline
\end{tabular}

Notes: 'Luvsansharav UO, Hirai I, Nakata A, et al. Prevalence of and risk factors associated with faecal carriage of CTX-M beta-lactamase-producing Enterobacteriaceae in rural Thai communities. J Antimicrob Chemother. 2012;67(7): 1769-1774 by permission of Oxford University Press. ${ }^{9}$ the number of CTX-M gene isolates was not matched with the total number of CTX-M due to the presence of dual CTX-M gene possession. The numbers in parentheses indicate the number of strains. $* P<0.000$ I, significantly different from the Vietnam group. ${ }^{* * P}<0.0$ I, significantly different from the Vietnam group. 
majority of ESBL-producing Enterobacteriaceae isolated in both Laos and Vietnam harbored CTX-M type genes (more than the $92 \%$ of ESBL phenotype strains) assessed by the multiplex PCR.

The genotyping of CTX-M gene positive isolates showed that both the CTX-M-1 (47.5\% and 33\%) and -9 group $(47.5 \%$ and $64.1 \%)$ were the most predominant genotype. While the CTX-M-2 (0\% and $1.0 \%)$ and -8 group $(5.0 \%$ and $1.9 \%$ ) were the lowest rates in the Laotian and Vietnamese residents, respectively (Table 1$)$.

The phylogenetic groups of the CTX-M ESBL-producing $E$. coli isolates were also determined. The most frequently detected phylogenetic group was A $(50.0 \%$ and $38.6 \%)$ followed by D (25\% and $25.7 \%)$ in the Laotian and Vietnamese residents, respectively. The least detected phylogenetic groups were the B1 and B2 groups (12.5\%) in Laotian residents and the B2 group (13.9\%) in Vietnamese residents (Table 2).

\section{Discussion}

Worldwide, the prevalence of ESBL-producing bacteria in the clinical setting has been well studied. ${ }^{1,12}$ However, the microbiological state of ESBL-producing bacteria in the community setting, particularly in Southeast Asia, is unclear, even though significant increases in the frequency of ESBL-producing bacteria in community isolates have been reported. ${ }^{13}$ On the other hand, the observation of CTX-M type ESBL-producing bacteria in community strains is consistent with their emergence from a widespread reservoir. ${ }^{14}$ In this regard, our previous study revealed the high prevalence of CTX-M type ESBL-producing Enterobacteriaceae in a local community in Thailand. ${ }^{4}$ However, it is still unclear whether this high prevalence of ESBL-producing bacteria can be found in other Southeast Asian countries as well. Therefore, in the present study, two local communities in Laos and Vietnam, which are geographically different, were chosen as representative communities on the Indochinese peninsula.

Table 2 Phylogenetic groups of the CTX-M extended-spectrum $\beta$-lactamase-producing Escherichia coli isolates

\begin{tabular}{|c|c|c|c|c|c|c|}
\hline \multirow{2}{*}{$\begin{array}{l}\text { Phylogenetic } \\
\text { group }\end{array}$} & \multicolumn{2}{|c|}{ Thailand $^{\mathrm{a}}$} & \multicolumn{2}{|l|}{ Laos } & \multicolumn{2}{|c|}{ Vietnam } \\
\hline & $\begin{array}{l}\text { No of } \\
\text { isolates }\end{array}$ & $\%$ & $\begin{array}{l}\text { No of } \\
\text { isolates }\end{array}$ & $\%$ & $\begin{array}{l}\text { No of } \\
\text { isolates }\end{array}$ & $\%$ \\
\hline$A$ & 114 & 48.7 & 20 & 50.0 & 39 & 38.6 \\
\hline BI & 67 & 28.6 & 5 & 12.5 & 22 & 21.8 \\
\hline B2 & 16 & 6.8 & 5 & 12.5 & 14 & 13.9 \\
\hline $\mathrm{D}$ & 37 & 15.8 & 10 & 25.0 & 26 & 25.7 \\
\hline Total & 234 & 100 & 40 & 100 & 101 & 100 \\
\hline
\end{tabular}

Note: a Luvsansharav UO, Hirai I, Nakata A, et al. Prevalence of and risk factors associated with faecal carriage of CTX-M beta-lactamase-producing Enterobacteriaceae in rural Thai communities. J Antimicrob Chemother. 2012;67(7):1769-1774 by permission of Oxford University Press. ${ }^{9}$
The study protocol and conditions of this present study were similar to those in our previous study performed in Thailand. ${ }^{9}$ While the age and sex of the participants differed among the three countries, this was unlikely to affect the prevalence of ESBL-producing bacteria, as the effects of age and sex on the risk of ESBL-producing bacteria carriage are reportedly limited. ${ }^{9}$ The concentration of cefotaxime used in the selection medium was different between the two communities. Our preliminary study with $2 \mathrm{mg} / \mathrm{L}$ cefotaxime in Vietnam showed a relatively low prevalence in comparison with that of Laos and Thailand. Therefore, we reduced the concentration of cefotaxime to $1 \mathrm{mg} / \mathrm{L}$, which is recommended for screening ESBLproducing bacteria by $\mathrm{CLSI}^{7}$ to detect more ESBL-producing bacteria than with $2 \mathrm{mg} / \mathrm{L}$. As shown in Table 1, the prevalence of ESBL-producing Enterobacteriaceae at $1 \mathrm{mg} / \mathrm{L}$ cefotaxime was still relatively low in Vietnam (ESBL phenotype, 51\%; CTX-M gene, 47\%) compared with the prevalence rates in Laos and Thailand. Nevertheless, the present study revealed a high prevalence of ESBL-producing bacteria in the residents of the two communities in Laos and Vietnam.

The majority of ESBL genes were CTX-M, accounting for $97.5 \%, 92.1 \%$, and $94.8 \%$ of ESBL-producing Enterobacteriaceae isolated in Laos, Vietnam, and Thailand, respectively. The widespread use of cefotaxime or ceftriaxone has been proposed as a reason for the emergence of CTX-M enzymes. ${ }^{14}$ The CTX-M subclasses were also investigated for characterization of the ESBL-producing bacterial dissemination in the community. Worldwide, the CTX-M-1 (CTX-M-15) group has been reported to be the dominant group of CTX-M ESBLproducing bacteria, followed by the CTX-M-9 (CTX-M-14) group, as determined by the Study for Monitoring Antimicrobial Resistance Trends using clinical isolates $;{ }^{15}$ the results of the present study corresponded with these previous findings.

It has been pointed out that the use of antibiotics in agriculture may contribute to the spread of antibiotic resistance in farm animals and subsequently result in transmission to humans. ${ }^{16}$ In fact, in the communities assessed in this study, household subsistence farming was common, indicating that the residents were likely in close contact with farm animals. In this regard, a recent study carried out in Korea reported that the most predominant CTX-M-6 type in farm animals, the farm environment, and farm workers was CTX-M-9, followed by CTX-M-1. ${ }^{17}$ The reasons for this observed dominance of CTX-M-1 and CTX-M-2 in the community and agriculture settings are not clear. However, clonal expansion of CTX-M ESBL-producing bacteria, such as E. coli ST131 with CTXM-15 (CTX-M-1 group), ${ }^{18}$ or horizontal dissemination of certain plasmids carrying the CTX-M gene ${ }^{19}$ may represent potential mechanisms. 
Assessment of the phylogenetic groups of the CTX-MESBLproducing bacteria isolated showed dominance of A followed by D in Laotian and Vietnamese residents. Similarly, in the People's Republic of China, phylogenetic groups A and D have been reported to be prevalent among ESBL-producing $E$. coli strains in asymptomatic carriers. ${ }^{20}$ On the other hand, a report on the population genetics of $E$. coli stated that commensal $E$. coli strains isolated from Asia mainly belonged to phylogenetic groups A and $\mathrm{B} 1,{ }^{21}$ whereas other studies have reported that a recent worldwide dissemination of CTX-M-14 and CTX-M-15 was likely driven by epidemic $E$. coli strains belonging to phylogenetic group B2 (ST131). ${ }^{22-24}$ Even though multi locus sequence typing was not conducted in this study, since the number of ESBL-producing bacteria belonging to $\mathrm{B} 2$ was limited in these communities, a possible clonal outbreak of CTX-M ESBL-producing E. coli B2 ST131 was considered unlikely.

Despite a limited number of participants, the results obtained in this study showed a wide dissemination of ESBL-producing bacteria among community residents in the Indochinese peninsula. These residents may be reservoirs for antibiotic resistance in the community and may contribute to the shortfalls in infection control and public health management.

\section{Acknowledgments}

This work was supported by the Japan Science and Technology Agency (JST)/Japan International Cooperation Agency (JICA) as part of the Science and Technology Research Partnership for Sustainable Development (SATREPS), and KAKENHI, the Ministry of Education, Culture, Sports, Science and Technology, Japan. We sincerely thank H Watabe, UO Luvsansharav, K Izawa, BTK Ngan, NTA Tuyet, HTT Van, and PTT Ha for their excellent technical assistance.

\section{Disclosure}

The authors report no conflicts of interest in this study.

\section{References}

1. Morrissey I, Hackel M, Badal R, Bouchillon S, Hawser S, Biedenbach D. A Review of Ten Years of the Study for Monitoring Antimicrobial Resistance Trends (SMART) from 2002 to 2011. Pharmaceuticals (Basel). 2013;6(11):1335-1346.

2. Falagas ME, Karageorgopoulos DE. Extended-spectrum beta-lactamaseproducing organisms. J Hosp Infect. 2009;73(4): 345-354.

3. Sasaki T, Hirai I, Niki M, et al. High prevalence of CTX-M beta-lactamase-producing Enterobacteriaceae in stool specimens obtained from healthy individuals in Thailand. JAntimicrob Chemother. 2010;65(4):666-668.

4. Luvsansharav UO, Hirai I, Niki M, et al. Analysis of risk factors for a high prevalence of extended-spectrum \{beta\}-lactamase-producing Enterobacteriaceae in asymptomatic individuals in rural Thailand. JMed Microbiol. 2011;60(Pt 5):619-624.
5. Hsueh PR, Hoban DJ, Carmeli Y, et al. Consensus review of the epidemiology and appropriate antimicrobial therapy of complicated urinary tract infections in Asia-Pacific region. J Infect. 2011;63(2):114-123.

6. Tian SF, Chen BY, Chu YZ, Wang S. Prevalence of rectal carriage of extended-spectrum beta-lactamase-producing Escherichia coli among elderly people in community settings in China. Can J Microbiol. 2008;54(9):781-785.

7. Cockerill FR. Clinical and Laboratory Standards Institute. Performance Standards for Antimicrobial Susceptibility Testing: Twenty-first Informational Supplement M100-S21. CLSI: PA, USA; 2011.

8. jlindquist.net [homepage on the Internet]. University of Wisconsin-Madison Microbiology. Available from: http://www.jlindquist.net/ generalmicro/102bactid.html. Accessed October 20, 2014.

9. Luvsansharav UO, Hirai I, Nakata A, et al. Prevalence of and risk factors associated with faecal carriage of CTX-M beta-lactamase-producing Enterobacteriaceae in rural Thai communities. JAntimicrob Chemother. 2012;67(7):1769-1774.

10. Pitout JD, Hossain A, Hanson ND. Phenotypic and molecular detection of CTX-M-beta-lactamases produced by Escherichia coli and Klebsiella spp. J Clin Microbiol. 2004;42(12):5715-5721.

11. Luvsansharav UO, Hirai I, Niki M, et al. Prevalence of fecal carriage of extended-spectrum beta-lactamase-producing Enterobacteriaceae among healthy adult people in Japan. $J$ Infect Chemother. 2011;17(5):722-725.

12. Ghafourian S, Sadeghifard N, Soheili S, Sekawi Z. Extended Spectrum Beta-lactamases: Definition, Classification and Epidemiology. Curr Issues Mol Biol. 2014;17:11-22.

13. Rodriguez-Bano J, Navarro MD, Romero L, et al. Epidemiology and clinical features of infections caused by extended-spectrum betalactamase-producing Escherichia coli in nonhospitalized patients. J Clin Microbiol. 2004;42(3):1089-1094.

14. Bonnet R. Growing group of extended-spectrum beta-lactamases: the CTX-M enzymes. Antimicrob Agents Chemother. 2004;48(1):1-14.

15. Lascols C, Hackel M, Hujer AM, et al. Using nucleic acid microarrays to perform molecular epidemiology and detect novel beta-lactamases: a snapshot of extended-spectrum beta-lactamases throughout the world. J Clin Microbiol. 2012;50(5):1632-1639.

16. Okeke IN, Laxminarayan R, Bhutta ZA, et al. Antimicrobial resistance in developing countries. Part I: recent trends and current status. Lancet Infect Dis. 2005;5(8):481-493.

17. Tamang MD, Nam HM, Gurung M, et al. Molecular characterization of CTX-M beta-lactamase and associated addiction systems in Escherichia coli circulating among cattle, farm workers, and the farm environment. Appl Environ Microbiol. 2013;79(13):3898-3905.

18. Rogers BA, Sidjabat HE, Paterson DL. Escherichia coli O25b-ST131: a pandemic, multiresistant, community-associated strain. JAntimicrob Chemother. 2011;66(1):1-14.

19. Coque TM, Baquero F, Canton R. Increasing prevalence of ESBLproducing Enterobacteriaceae in Europe. Euro Surveill. 2008;13(47).

20. Li B, Sun JY, Liu QZ, Han LZ, Huang XH, Ni YX. High prevalence of CTX-M beta-lactamases in faecal Escherichia coli strains from healthy humans in Fuzhou, China. Scand J Infect Dis. 2011;43(3):170-174.

21. Tenaillon O, Skurnik D, Picard B, Denamur E. The population genetics of commensal Escherichia coli. Nat Rev Microbiol. 2010;8(3):207-217.

22. Pitout JD, Gregson DB, Campbell L, Laupland KB. Molecular characteristics of extended-spectrum-beta-lactamase-producing Escherichia coli isolates causing bacteremia in the Calgary Health Region from 2000 to 2007: emergence of clone ST131 as a cause of community-acquired infections. Antimicrob Agents Chemother. 2009;53(7):2846-2851.

23. Coque TM, Novais A, Carattoli A, et al. Dissemination of clonally related Escherichia coli strains expressing extended-spectrum beta-lactamase CTX-M-15. Emerg Infect Dis. 2008;14(2):195-200.

24. Peirano G, Pitout JD. Molecular epidemiology of Escherichia coli producing CTX-M beta-lactamases: the worldwide emergence of clone ST131 O25:H4. Int J Antimicrob Agents. 2010;35(4):316-321. 
Infection and Drug Resistance

\section{Publish your work in this journal}

Infection and Drug Resistance is an international, peer-reviewed openaccess journal that focuses on the optimal treatment of infection (bacterial, fungal and viral) and the development and institution of preventive strategies to minimize the development and spread of resistance. The journal is specifically concerned with the epidemiology of antibiotic
Dovepress

resistance and the mechanisms of resistance development and diffusion in both hospitals and the community. The manuscript management system is completely online and includes a very quick and fair peerreview system, which is all easy to use. Visit http://www.dovepress.com/ testimonials.php to read real quotes from published authors.

Submit your manuscript here: http://www.dovepress.com/infection-and-drug-resistance-journal 